\title{
Secagem por aspersão (spray drying) de extratos vegetais: bases e aplicações
}

\author{
Olivia Werner Oliveira, Pedro Ros Petrovick*
}

\author{
Laboratório de Desenvolvimento Galênico; Programa de Pós-graduação em Ciências Farmacêuticas, Curso de \\ Farmácia; Universidade Federal do Rio Grande do Sul, Avenida Ipiranga, 2752, 90610-000 Porto Alegre-RS, Brasil.
}

\begin{abstract}
RESUMO: A maioria dos medicamentos fitoterápicos registrados no Brasil apresenta-se sob a forma farmacêutica sólida, utilizando extratos secos como principal matéria-prima ativa. A técnica de secagem por aspersão (spray drying) tem sido amplamente aplicada na obtenção de extratos secos com melhores características tecnológicas e maior concentração de constituintes com atividade biológica. As propriedades físico-químicas dos produtos produzidos por spray drying são influenciadas por fatores relacionados ao processo, à formulação (material de entrada) e ao equipamento. Nesta revisão são apresentados e discutidos resultados de trabalhos relacionados a parâmetros de processo e formulação, e as aplicações da técnica com enfoque no desenvolvimento de extratos secos oriundos de vegetais, principalmente da flora medicinal brasileira.
\end{abstract}

Unitermos: Secagem por aspersão, produtos naturais, extratos secos, processo.

\begin{abstract}
Spray drying of plant extracts: basic remarks and application". In Brazil, the majority of the approved phytomedicines are formulated as solid dosage forms containing plant dried extracts as active component. Spray drying technique has been widely used to obtain dried extracts presenting better technological characteristics and greater concentration of biological active constituents. Physicochemical properties of such products depend on factors related to process, formulation (inlet material) and equipment. This review presents and discusses some studies related to parameters of process and formulation, as well as some technical applications focusing on the development of dried extract from plants, mainly from the Brazilian medicinal flora.
\end{abstract}

Keywords: Spray drying, natural products, dry extracts, process.

\section{INTRODUÇÃO}

Em um contexto geral, a utilização de extratos de plantas para propósitos medicinais tem suscitado maior interesse nos últimos anos. No Brasil encontramse registrados 512 medicamentos fitoterápicos, dos quais mais de $70 \%$ apresentam-se como formas farmacêuticas sólidas (Carvalho et al., 2008). A matéria-prima para estes produtos é constituída, majoritariamente, por extratos secos, os quais dentre as suas vantagens incluem a maior estabilidade química, físico-química e microbiológica, mais fácil padronização, maior concentração de compostos ativos e mais elevada capacidade de transformação em diferentes tipos de formas farmacêuticas sólidas. Entre os procedimentos de secagem, destaca-se a técnica de secagem por aspersão (spray drying).

Uma das operações mais frequentes na produção de medicamentos é a secagem, sendo empregada no processamento de diversos materiais para a obtenção de pós e grânulos. O objetivo principal da secagem farmacêutica é a retirada da água, responsável por propiciar um meio reacional propício para reações químicas, fenômenos físicos e proliferação microbiana (De Souza et al., 2006b; Rankell et al., 2001; Santos, 2000).

Tendo em vista a predominância de produtos secos oriundos de vegetais como constituintes de medicamentos fitoterápicos e da técnica de secagem por aspersão (spray drying) como passo tecnológico da obtenção dos mesmos, este trabalho objetiva apresentar uma revisão dos principais aspectos tecnológicos relacionados ao processo e aplicações da técnica na produção de fitomedicamentos, compilando, em sua maioria, trabalhos realizados no Brasil que utilizaram esta técnica.

\section{Etapas do processo de secagem por aspersão}

O processo de secagem por aspersão consiste de três etapas fundamentais. Na primeira fase, o fluído é disperso como gotículas, produzindo uma grande área superficial. Na segunda, ocorre contato destas com uma corrente de ar aquecido, havendo transferência de calor. $\mathrm{Na}$ terceira etapa acontece a evaporação do solvente e 
a formação da partícula sólida (Figura 1) (Nonhebel \& Moss, 1971; Masters, 1985; Broadhead et al., 1992; Shaw, 1997; Rankell et al., 2001).

\section{Aspersão do produto}

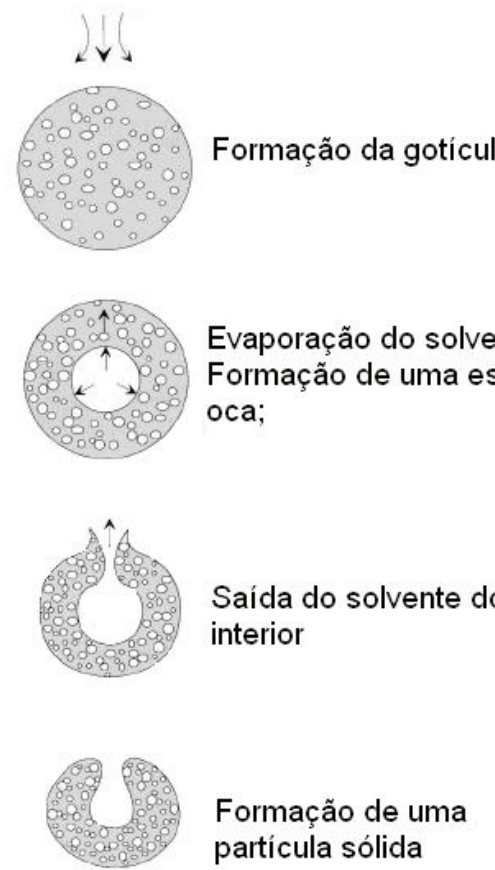

Figura 1. Formação de partícula por secagem por aspersão (adaptada de Cao et al., 2000).

Com a transferência de calor do ar aquecido às gotículas, o líquido da superfície evapora-se rapidamente. As partículas solidificadas geralmente apresentam o mesmo tamanho e forma da gotícula que as originou. $\mathrm{Na}$ última etapa, o produto de secagem é transportado por uma corrente de ar sendo posteriormente coletado (Broadhead et al., 1992; Shaw, 1997; Rankell et al., 2001).

A evaporação superficial da gotícula conduz à formação de uma camada de material seco externa. Através desta camada, o líquido situado no interior da gotícula propaga-se para o exterior. Dependendo da elasticidade e da permeabilidade da crosta, serão produzidos distintos materiais secos como esferas intactas, com superfície imperfeita ou fragmentada, sólidas ou ocas (Rankell et al., 2001). A Figura 2 apresenta fotomicrografias de dois extratos diferentes de Maytenus ilicifolia secos por spray drying, com disco giratório em torre de secagem por aspersão. Os extratos foram produzidos da mesma maneira utilizando temperatura de entrada de $180^{\circ} \mathrm{C}$, velocidade do aspersor de $9500 \mathrm{rpm}$ e 30\% de Aerosil (Oliveira, 2008).

\section{Fatores que influenciam o processo}

Um das respostas mais relevantes afetada pelas condições de operação do processo é a qualidade do produto
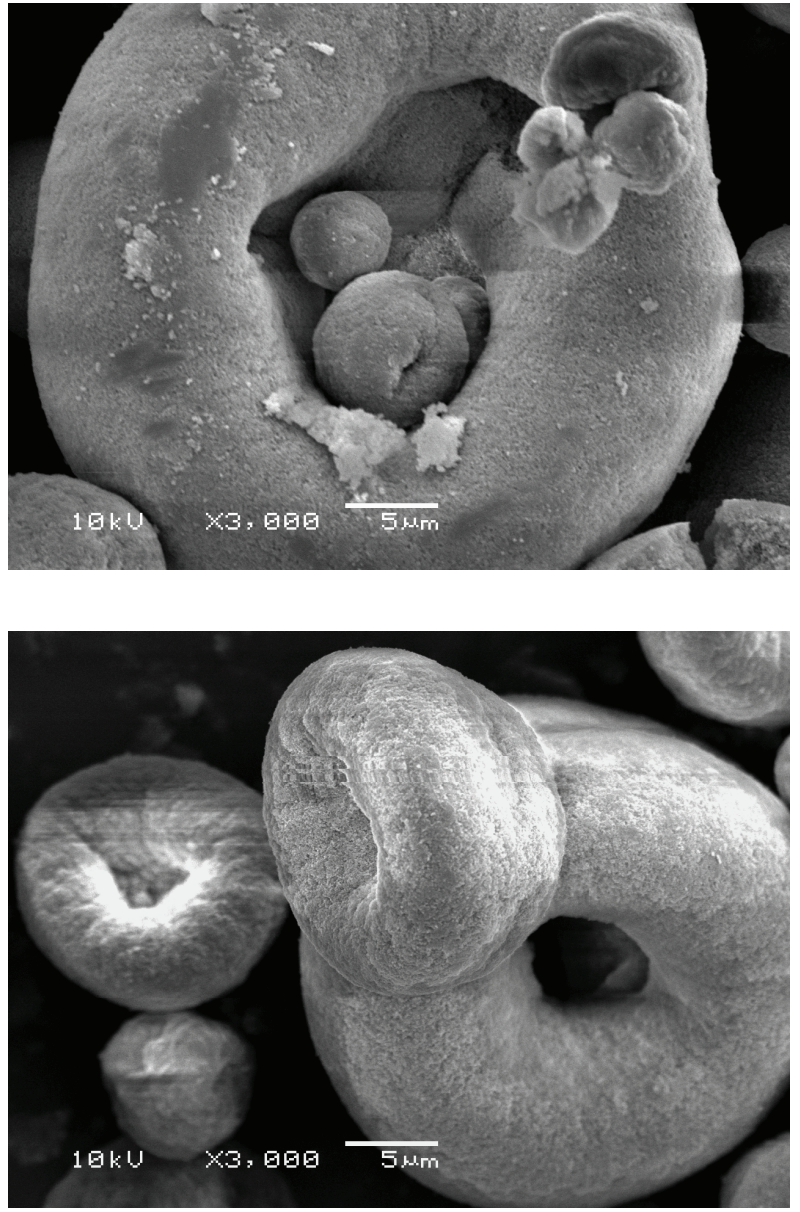

Figura 2. Fotomicrografias de produto seco de Maytenus ilicifolia em aumento de 3000x.

resultante. As variáveis devem ser controladas visando à obtenção de rendimento e de teor de umidade adequados, estabilidade química, minimização da aderência de partículas na câmara de secagem (sticking) e características tecnológicas específicas. As propriedades do produto são normalmente determinadas pelos fatores relacionados às características do material de entrada e do processamento, isto é, parâmetros de operação e equipamento (Quadro 1).

\section{Influência do material de entrada}

Entre os fatores relacionados às características do material de entrada, o uso de adjuvantes na técnica de secagem por aspersão é uma prática muito comum. São utilizados como adjuvantes neste processo: amido, ciclodextrinas, dióxido de silício coloidal, fosfato tricálcico, gelatina, goma arábica, lactose, maltodextrina entre outros (Vasconcelos et al., 2005; Silva Júnior et al., 2006).

Para a secagem de extratos derivados de plantas, a seleção e o uso adequado de adjuvantes no processo de spray drying é uma fase de fundamental importância, visto que determina a estabilidade e a qualidade dos mesmos, podendo inclusive afetar as características de biodisponibilidade. 
O dióxido de silício coloidal, que apresenta elevada superfície específica e alto poder sorvente, tem sido amplamente empregado, apresentando excelentes resultados na obtenção de produtos secos por aspersão a partir de soluções extrativas de diferentes espécies vegetais (De Campos, 1996; De Souza, 1997).

A influência da concentração de dióxido de silício coloidal foi analisada na secagem de soluções extrativas de Maytenus ilicifolia Martius ex Reissek. A adição deste adjuvante a $10 \%$ e a $20 \%$, em relação ao teor de sólidos na solução extrativa, causou redução significativa na higroscopicidade dos produtos secos, não ocorrendo formação de aglomerados (Carvalho, 1997).

De Paula et al. (1998) e Teixeira (1996) avaliaram a influência da composição qualitativa na secagem de soluções extrativas de Achyrocline satureioides (Lam.) DC. A substituição do dióxido de silício coloidal por $\beta$-ciclodextrina ou por celulose microcristalina teve efeito negativo sobre a estabilidade dos produtos obtidos frente à umidade residual.

Extratos secos de Passiflora edulis Sims. contendo apenas dióxido de silício coloidal (Aerosil 200) como adjuvante de secagem apresentaram melhores características tecnológicas quando comparados a extratos com hidrolisado de gelatina (Gelita-Sol P) ou a mistura dos dois em diferentes proporções (De Souza et al., 2000).

A viscosidade, o conteúdo de sólidos, a tensão superficial do produto fluido a secar, além do fluxo de alimentação, influenciam diretamente o tamanho de partícula (List \& Schmidt, 1989; Shaw, 1997).

A concentração de sólidos presentes no líquido de alimentação exerce grande impacto sobre a eficiência da operação de secagem. Devido ao custo do processo, o spray dryer deve operar com o máximo teor de sólidos possível, possibilitando uma utilização adequada do calor (Masters, 1985). Baixas concentrações de sólidos necessitam que grande quantidade de solvente seja eliminada ou requerem a adição de adjuvantes de secagem, visando à formação de partículas maiores e à otimização do rendimento do processo (De Campos, 1996).

A influência do teor de sólidos no material de partida é refletida no tamanho de partícula e na densidade do produto final. De acordo com Cao et al. (2000), o aumento no conteúdo de sólidos, eleva a viscosidade, resultando em pós com maior densidade. Além disso, quanto menor o conteúdo de sólidos em uma suspensão, maior o espaço oco interno da partícula (ballooning), porém as paredes tornam-se menos espessas.

Outro fator importante a ser considerado, é a viscosidade da formulação, pois esta interfere na formação de gotas esféricas. Deste modo, menos energia ou menor pressão são aplicadas quando a viscosidade for baixa. Por outro lado, a viscosidade elevada da formulação impede a formação adequada das gotas durante a aspersão (Soares, 2002), propiciando aumento no tamanho de partícula, devido à formação de gotículas maiores durante a etapa de aspersão (Foster \& Leatherman, 1995). Além disso, a tensão superficial do material a ser seco exerce influencia proporcional sobre a energia gasta para formar as gotículas. A adição de tensoativos é utilizada com a finalidade de reduzir a tensão superficial, propiciando a formação de gotículas menores e aumento na velocidade de aspersão (De Campos, 1996; Soares, 2002).

No que tange a utilização de solventes em secagem por aspersão, além da água, é empregada grande variedade de líquidos orgânicos. $\mathrm{Na}$ indústria farmacêutica, álcoois, como etanol, metanol e isopropanol são os solventes orgânicos preferenciais. Um líquido que apresenta ponto de ebulição baixo pode ser a única opção para materiais termolábeis. Assim sendo, as características de secagem dos solventes também devem ser levadas em consideração. Apesar do processo de secagem ser eficiente quando os referidos solventes orgânicos são empregados, o risco de explosão torna a utilização muito perigosa. Devido a isso, um gás inerte, geralmente o nitrogênio, é utilizado em vez de ar, sendo para tanto necessário um sistema de ciclo fechado (Çelik \& Wendel, 2005).

\section{Influência do processo}

Em relação ao processo, um dos parâmetros de maior importância é a temperatura do ar de entrada, sendo determinante na qualidade do produto obtido. $\mathrm{O}$ aumento na temperatura do material de entrada facilita o processo de secagem, pois normalmente reduz a tensão superficial e a viscosidade, facilitando a formação de gotículas (Soares, 2002). A temperatura de entrada deve estar acima do ponto de ebulição do solvente utilizado. Ainda que a temperatura de entrada possa ser consideravelmente elevada, os sólidos em cada partícula nunca são aquecidos acima da temperatura de saída. A umidade do produto final de secagem é determinada pela temperatura de saída, que por sua vez é dependente da temperatura de entrada. A temperatura do produto aspergido estará aproximadamente $20 \mathrm{oC}$ abaixo da temperatura de saída. O melhor ajuste da temperatura de entrada e saída necessita ser estabelecido para otimização das características físicas do produto (De Campos, 1996; Aulton, 2002).

As mudanças morfológicas das partículas em diferentes locais da câmara de secagem foram avaliadas por Alamilla-Beltrán et al. (2005). Essas alterações foram relacionadas à umidade $\mathrm{e}$ às temperaturas do processo. Em temperaturas mais baixas foram observadas partículas com menor tamanho, que se apresentaram com uma fina crosta, compacta e irregular. $\mathrm{O}$ ajuste da velocidade de alimentação é realizado com a finalidade de que o líquido presente nas gotículas evapore antes que estas entrem em contato com as paredes da câmara de secagem. Velocidades de alimentação excessivas conduzem à diminuição da temperatura de saída e ao acúmulo do material sobre as paredes da câmara (Masters, 1985; Rankell et al., 2001). 
Através da avaliação da temperatura do ar de saída e da inspeção das paredes da câmara de secagem é determinado o fluxo de alimentação. Se a temperatura do ar de entrada permanecer constante, uma diminuição na taxa de alimentaçãodolíquidoacarretaráemaumentonatemperatura do material de saída (Masters, 1985; Rankell et al., 2001).

Os componentes presentes em todos os equipamentos são: distribuidor de alimentação, aspersor, fornecedor de ar quente (a), câmara de secagem (b), separador sólido-gás (c) e sistema de recolhimento do produto (d), conforme Figura 3 (Masters, 1985).

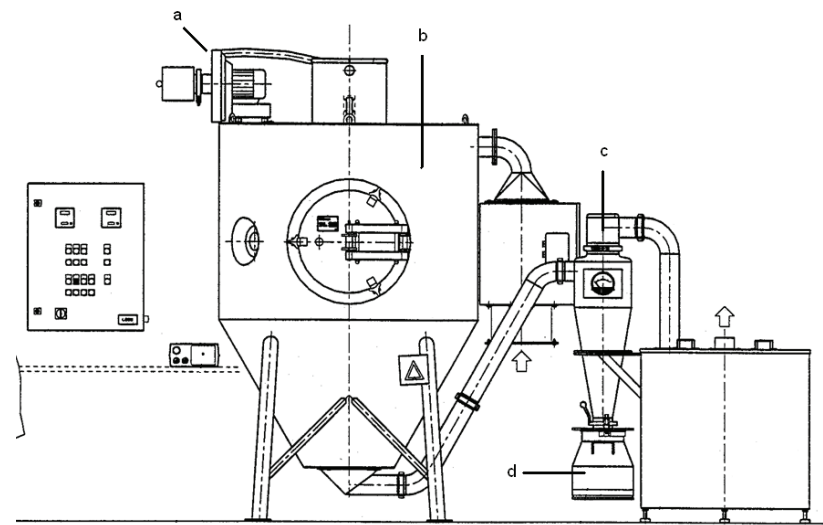

Figura 3. Torre de secagem por aspersão, Production Minor (Niro, GEA)

Através do ciclone, denominado coletor primário, ocorre a separação do produto sólido do gás efluente. O produto que atinge as paredes da câmara de secagem é recolhido no fundo da mesma. O produto recolhido no ciclone apresenta menor tempo de retenção em relação ao produto que permanece na da câmara, sendo este frequentemente mais denso e propenso a um aquecimento mais prolongado devido ao aumento do tempo de permanência. O produto final seco é, normalmente, resultante da mistura de ambos os produtos.

Existem no mercado diversos tipos de secadores por aspersão. A escolha dos mesmos depende do material a ser seco e das características pretendidas para o produto final (Masters, 1985; Filková \& Mujumdar, 1987; Shaw, 1997; Rankell et al., 2001).

A distribuição e o tamanho de partícula estão relacionados ao tamanho das gotículas formadas pelo processo de aspersão. Portanto, a escolha do tipo do aspersor é fundamental (Filková \& Mujumdar, 1987; Broadhead et al., 1992).

Os aspersores são classificados em três tipos básicos: de pressão, pneumáticos e de disco giratório, sendo estes dois últimos os mais difundidos (Figura 4).
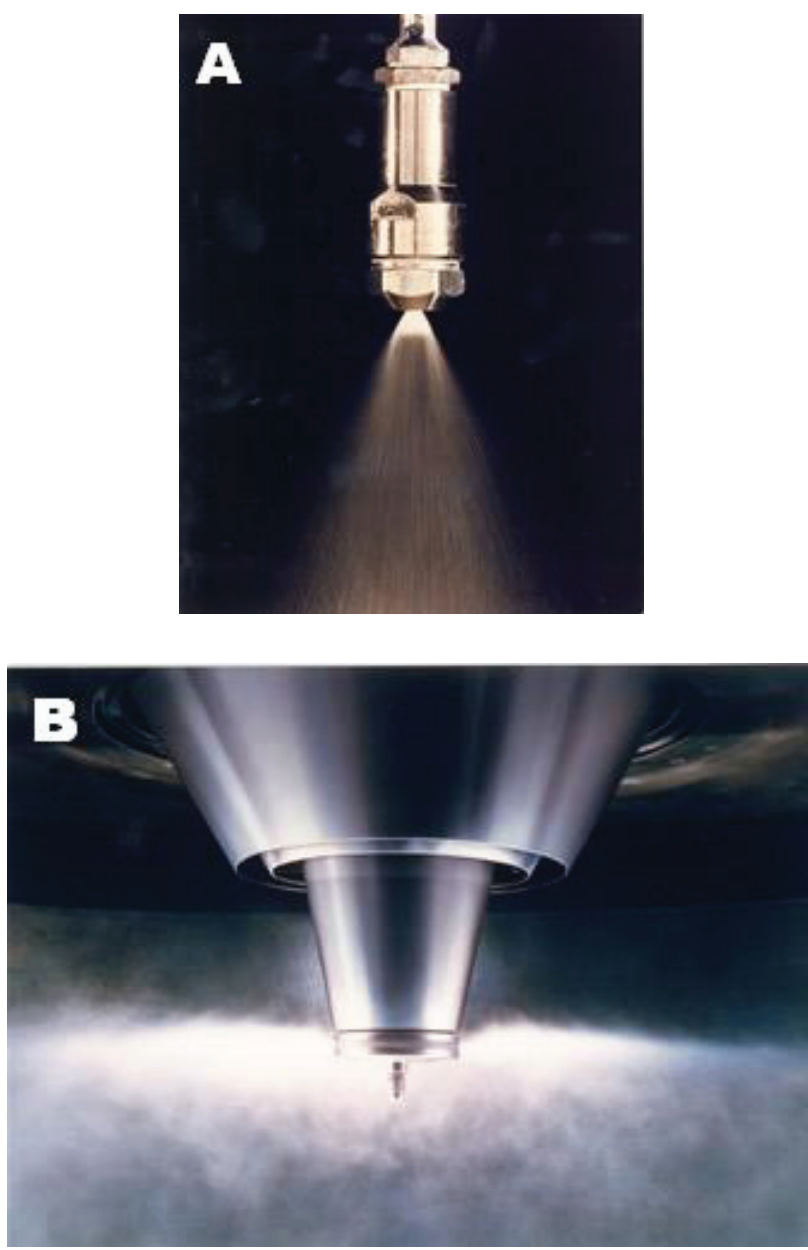

Figura 4. Aspersor pneumático (A); aspersor de disco giratório (B) (Niro Inc.)

Os aspersores pneumáticos e de pressão apresentam a desvantagem de serem mais propensos à oclusão dependendo do material utilizado, embora permitam a obtenção de partículas de tamanhos diversos, de acordo com a escolha do diâmetro interno do bocal injetor. Os aspersores de disco giratório possuem maior aplicação na secagem de produtos farmacêuticos, pois são efetivos para soluções e suspensões, podendo ser empregados para secagem de líquidos de elevada viscosidade ou até mesmo pastas (Masters, 1985; Rankell et al., 2001). Dependendo do material de partida e da velocidade de rotação, o diâmetro médio das partículas obtidas pode variar de 15 a $250 \mu \mathrm{m}$ (Shaw, 1997). Podem ser citadas como vantagens do uso de aspersor de disco rotatório (Mujumdar, 2000; Filková \& Mujumdar, 1987): i. possibilidade da utilização de altas taxas de alimentação em apenas um disco; ii. aplicabilidade até mesmo para materiais abrasivos; e, iii. controle do tamanho de partícula por mudanças na velocidade do disco. Porém, esse tipo de aspersor apresenta como desvantagens o custo e o consumo de energia elevados em comparação aos outros, além da necessidade de câmaras de secagem com diâmetros grandes (Filková \& Mujumdar, 1987). 
Nos aspersores rotatórios (rotores), o fluído é conduzido ao centro de um disco rotatório, movendo-se em direção a seu limite periférico, sendo a força centrífuga responsável pela desintegração do líquido em gotículas. Velocidades angulares entre 10000 e 30000 rpm são necessárias para discos de diâmetro usual. O tamanho da partícula é inversamente proporcional a velocidade periférica do disco (Filková \& Mujumdar, 1987). Para promover uma densidade apropriada do pó, é necessário o conhecimento da influência dos parâmetros do processo sobre o tamanho da partícula e a distribuição dimensional das mesmas. A distribuição e o tamanho de partícula são relacionados ao tamanho das gotículas formadas pelo processo de aspersão. Portanto, uma predição bem sucedida do tamanho de partícula permite controlar as propriedades do pó como planejado (Filková \& Mujumdar, 1987; Broadhead et al., 1992).

Produtos de alta uniformidade granulométrica são produzidos por aspersores rotatórios, podendo-se controlar o tamanho de partícula através da alteração da velocidade de rotação do rotor. Em geral, a variação na velocidade de alimentação exerce menor impacto sobre as características dimensionais do produto, sendo menos pronunciada do que as modificações na velocidade de rotação (Filková \& Mujumdar, 1987).

As partículas apresentam-se como esferas ocas, exibindo às vezes um pequeno orifício na superfície (Figura 5), decorrente da vaporização do líquido contido no interior da esfera (Soares, 2002).

\section{Vantagens e desvantagens do processo}

O processo de secagem por aspersão apresenta diversas vantagens, tais como (Masters, 1985; Shaw, 1997; Aulton, 2002):

${ }^{\circ}$ seleção adequada do equipamento com base nas características pretendidas para o produto final;

o controle da uniformidade e do tamanho das partículas do produto pela manipulação das variáveis do processo;

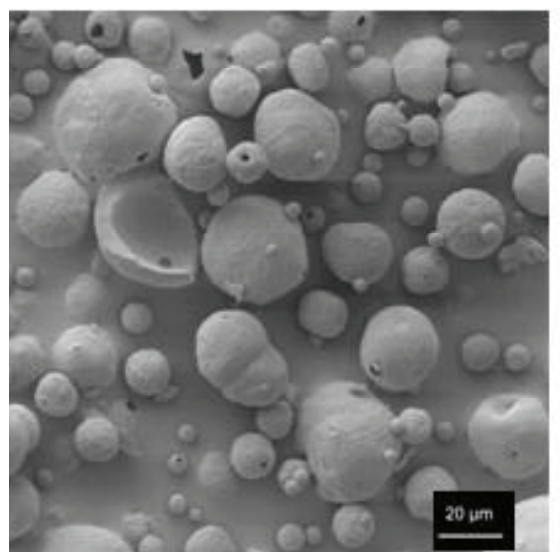

- processo contínuo, podendo ser alteradas condições de operação sem a necessidade de interrupção;

${ }^{\circ}$ rapidez e rendimento. A evaporação ocorre em frações de segundos, em virtude da formação de inúmeras gotículas que proporcionam uma grande área superficial para trocas térmicas e transferência de massa;

o baixa agressividade ao produto, o que a faz apropriada para produtos termossensíveis devido ao curto tempo de contato com a fonte de calor, podendo assim, ser empregada com sucesso na produção de produtos intermediários para fitomedicamentos;

${ }^{\circ}$ as partículas resultantes apresentam forma esférica uniforme e uma rápida dissolução, devido à grande área específica;

${ }^{\circ}$ os custos do processo são baixos.

Alguns sistemas podem operar em modo de circuito-fechado com um gás inerte para reduzir a oxidação do produto (Aulton, 2002). Entre as desvantagens acerca da utilização da técnica de secagem por este método podem ser citadas (Broadhead et al., 1992; Wendel \& Çelik,1998): i. o equipamento apresenta grandes dimensões, necessitando de instalações físicas adequadas; ii. o custo inicial é alto, pois necessita de investimento em instalações. Porém, o valor do produto final pode justificar o ônus inicial.

\section{Aplicações da técnica e sua interferência na qualidade dos produtos}

Os trabalhos relacionados à técnica de secagem por aspersão direcionam-se para a obtenção do produto seco e para a utilização do mesmo em ciclos de produção de formas farmacêuticas. Sob o aspecto de produto intermediário de processo, produtos secos por aspersão são valorizados devido à sua elevada estabilidade química e microbiológica, e maior facilidade de transporte e de armazenamento. Por outro lado, a elevada carga de constituintes vegetais e reduzidas dimensões, acarretam problemas de fluxo e causam aumento da superfície específica, favorecendo um comportamento desfavorável frente à umidade ambiental (Soares et al., 2005).

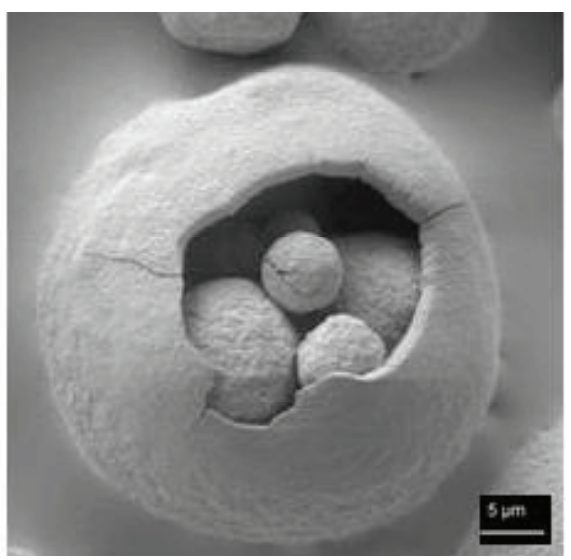

Figura 5. Microfotografia de produto seco por aspersão de Maytenus ilicifolia 500 e 2000x (Soares, 2002). 
Deve-se considerar que o processo de spray drying exerce influência não somente sobre as características tecnológicas, físicas e químicas dos produtos obtidos, podendo também interferir na sua atividade biológica.

A influência dos parâmetros temperatura de entrada e concentração de dióxido de silício coloidal (Aerosil 200) sobre as características de produtos secos por aspersão foi investigada por Vasconcelos e colaboradores (2005). Tais produtos foram produzidos a partir de extratos etanólicos de Schinus terebinthifolius Raddi, utilizada popularmente devido às atividades antimicrobiana, cicatrizante e antiinflamatória (Vasconcelos et al., 2005).

Os resultados do estudo revelaram que o rendimento do processo aumentou nos níveis mais altos de Aerosil. Na concentração de $30 \%$ obtiveram os menores valores para a umidade residual, independentemente da temperatura de entrada. A higroscopicidade e a umidade residual dos produtos foram inversamente proporcionais ao aumento da temperatura de entrada e à concentração do adjuvante. Com base nas respostas avaliadas, as condições operacionais mais adequadas foram $30 \%$ de adjuvante, auma temperatura de $140{ }^{\circ} \mathrm{C}$, obtendo rendimento acima de $80 \%$.

Produtos secos por aspersão a partir de solução extrativa aquosa de Ilex paraguariensis St. Hill. foram produzidos e avaliados em estudo realizado por Da Silva (2007). O emprego de Aerosil ${ }^{\circledR} 200$ na concentração de 30 $\%$ propiciou melhores características tecnológicas e maior estabilidade frente à luz quando comparado a extratos secos com o mesmo adjuvante na concentração de $15 \%$. Extratos fluídos de Symphytum officinale L. foram submetidos à secagem por aspersão utilizando como adjuvante de secagem hietolose (hidróxi-etilcelulose) na concentração de $1,5 \%$. Análises dos perfis térmicos e cromatográficos de extratos liofilizados e secos por aspersão comprovaram que a secagem não acarretou nenhuma degradação ao produto (Silva Júnior et al., 2006).

$\mathrm{O}$ processo de spray drying não se limita somente à secagem de extratos fluídos, se estende também à microencapsulação de nanopartículas produzidas a partir de extratos de plantas. Microcápsulas contendo nanopartículas de Salvia miltiorrhiza Bunge, com diâmetro médio de 133,5 nm, foram produzidas por spray dryer utilizando diferentes proporções de gelatina e carmelose sódica. A otimização dos parâmetros de secagem foi verificada e a condição mais adequada foi temperatura de entrada de $80{ }^{\circ} \mathrm{C}$, fluxo de $4 \mathrm{~mL} / \mathrm{min}$ e fluxo de gás de $357 \mathrm{~L} / \mathrm{h}$ ( $\mathrm{Su}$ et al., 2008).

$\mathrm{Na}$ indústria alimentícia a técnica também é utilizada para secagem de polpas de frutas (açaí, abacaxi, melancia) devido à boa qualidade conferida ao pó resultante e às facilidades de transporte e armazenamento, além da maior estabilidade físicoquímica. Para tal finalidade, geralmente é utilizada a maltodextrina como adjuvante de secagem (Abadio et al., 2004; Quek et al., 2007; Tonon et al., 2008).

$$
\text { A secagem por aspersão tem sido }
$$

utilizada freqüentemente na obtenção de produtos tecnológicos intermediários destinados à produção de diversos tipos de formas farmacêuticas. Pomadas utilizando extrato seco de Achyrocline satureioides (Lam.) DC foram desenvolvidas, avaliandose os adjuvantes utilizados no processo de secagem no que tange às características físicas da formulação, tais como, espalhamento, viscosidade, $\mathrm{pH}$ e índice de óleo. Dependendo da composição qualitativa e quantitativa dos produtos secos foram observados comportamentos diferenciados (De Paula et al., 1998).

Comprimidos contendo alto teor de produtos secos por aspersão de Passiflora edulis Sims. foram produzidos por compressão direta, tendo sido utilizado fosfato tricálcico como adjuvante de secagem. A influência da concentração de dióxido de silício coloidal e da croscarmelose sobre o tempo de desintegração e a dureza dos comprimidos foram avaliadas por meio de Desenho Composto Central. Os resultados obtidos neste estudo revelaram que a concentração de dióxido de silício coloidal aumentou proporcionalmente a dureza e a carboximetilcelulose cross-linked causou uma diminuição linear no tempo de desintegração (Linden et al., 2000).

As deficiências reológicas e compressionais de produtos secos por aspersão podem ser contornadas pela sua granulação. Nesse sentido, comprimidos com elevada concentração de extratos secos por spray drying de Maytenus ilicifolia Martius ex Reissek foram produzidos por dois métodos diferentes de granulação a seco e avaliados por Soares (2002).

O comportamento compressional de granulados obtidos a partir de produtos secos por aspersão de Phyllanthus niruri L. em máquinas de comprimir foi avaliado por Spaniol (2007), De Souza et al. (2006a) e Couto (2005), utilizando como adjuvante de secagem dióxido de silício coloidal.

Granulados a partir do produto seco por aspersão de Achyrocline satureioides (Lam.) DC foram produzidos por via seca por desagregação, com a finalidade de propiciar melhoramento nas propriedades de fluxo, características granulométricas e de compressibilidade, bem como aumento da estabilidade fisico-química. Os granulados produzidos apresentaram propriedades tecnológicas adequadas para a compressão. Além disso, foi constatado que os processos de secagem por spray drying e granulação não provocaram alterações nas propriedades químicas do material de partida. No entanto a afinidade pela umidade obrigou a realizar revestimento protetor dos granulados (Petrovick, 2006).

Este mesmo problema de instabilidade do produto seco por aspersão de Phyllanthus niruri L. foi enfrentado por duas estratégias tecnológicas distintas, pelo revestimento dos comprimidos obtidos (De Souza et al., 2005) e pela granulação com resina poliacrílica (De Souza et al., 2007). A viabilidade de produção de extratos secos 
de Rosmarinus officinalis L. por spray dying e leito de jorro foi comparada por Souza et al., 2008. Os extratos obtidos apresentaram problemas de fluxo e propriedades de compressão, além disso, ocorreu degradação dos compostos fenólicos, utilizados como marcadores químicos.

Extratos nebulizados e liofilizados de Achyrocline satureioides (Lam.) DC, preparados a partir de soluções extrativas obtidas por diferentes métodos e proporções de etanol, foram avaliados em relação ao efeito antiinflamatório por via oral. Foi constatado que a proporção de etanol, método de secagem e adição de polisorbato 80 influenciaram o efeito antiinflamatório dos extratos. Os extratos liofilizados e secos por aspersão provenientes de soluções extrativas contendo solventes menos polares (80\% etanol) tiveram sua atividade antiinflamatória melhorada na presença de polisorbato 80 e de dióxido de silício coiloidal (De Souza et al., 2007).

O potencial de uso de extratos derivados de $A$. satureioides, cuja atividade antiinflamatória é atribuída a flavonóides, tem suscitado interesse na separação e quantificação desses compostos (De Souza et al., 2002).

Procedendo a análise de extratos secos de Lippia alba Mill. N.E.Br., contendo diferentes proporções de dióxido de silício coloidal, polisorbato 80 e $\beta$-ciclodextrina, concluiu-se que apenas o extrato contendo unicamente dióxido de silício coloidal como adjuvante apresentou efeitos sedativos próximos ao extrato fluído. O processo de secagem não alterou as propriedades sedativas, porém, no que tange aos adjuvantes de secagem utilizados, estes exerceram influência sobre as mesmas (Zétola et al., 2002).

O comportamento térmico dos adjuvantes de secagem dióxido de silício coloidal e $\beta$-ciclodextrina foi verificado por análises em TG (termogravimetria) e DSC (calorimetria exploratória diferencial) para extrato seco de Albizia inopinata (Harms) G.P. Lewis, à qual são atribuídos efeitos vasodilatador e anti-hipertensivo. $\mathrm{O}$ extrato com $\beta$-ciclodextrina apresentou a melhor estabilidade e o dióxido de silício coloidal apresentou melhor aparência e menor estabilidade (De Medeiros et al., 2002).

Georgetti et al. (2008) avaliaram os efeitos da técnica de spray drying sobre as propriedades químicas e biológicas de extratos de soja. Os adjuvantes de secagem analisados foram dióxido de silício coloidal, amido e maltodextrina. Os extratos produzidos com dióxido de silício coloidal apresentaram melhores características de fluxo e menor tendência à aglomeração. Além disso, demonstraram níveis inferiores de degradação do conteúdo de polifenóis e menor redução da atividade antioxidante, quando comparados aos extratos contendo os demais adjuvantes.

Extratos secos por aspersão de Maytenus aquifolium Martius apresentaram atividade antiulcerogênica significativa em ratos, comprovando assim, que o processo de secagem por spray drying não provocou alterações na atividade biológica da planta (Bersani-Amado et al., 2000).

No que concerne à contaminação microbiana na produção de fitomedicamentos, esta ainda representa um desafio a ser superado, visto que as drogas vegetais podem apresentar um grande número de fungos e bactérias. A carga microbiana pode ser reduzida de acordo com o processo ao qual o material vegetal é submetido. Análises microbiológicas comparativas entre a droga pulverizada, a extração em fase líquida e o produto seco por aspersão, empregando Phyllanthus niruri L., revelaram haver diminuição significativa na carga microbiana, causada pelo processo, enquanto que a secagem por spray dryer, apesar da alta temperatura, não afetou a carga microbiana, apontando, portanto para os cuidados relacionados a este aspecto quando da preparação dos materiais de alimentação do processo de secagem (De Souza et al., 2006b). Alguns trabalhos que utilizam a operação de spray drying para secagem de produtos vegetais estão descritos no Quadro 2.

\section{CONCLUSÃO}

O tema abordado nessa revisão permite verificar que a técnica de secagem por aspersão apresenta diversas vantagens como, maior estabilidade físico-química do produto obtido e facilidade de sua derivação em outras formas farmacêuticas.

Para melhor aproveitamento desses benefícios e obtenção de extratos com características tecnológicas adequadas é necessária a avaliação criteriosa do processo de secagem, determinando parâmetros otimizados de operação específicos para cada formulação, devido ao fato da grande influência exercida pelos mesmos sobre o produto final.

Entre os diversos adjuvantes empregados nesse processo, o dióxido de silício coloidal é o mais utilizado e pesquisado na secagem de extratos vegetais.

Os extratos secos obtidos por spray drying encontram emprego como produtos finais ou intermediários, sobretudo em formas farmacêuticas sólidas, visto que no Brasil há uma predominância dessas no registro de medicamentos fitoterápicos. No estudo realizado foi observado que Achyrocline satureioides (Lam.) DC, Albizia inopinata (Harms) G.P. Lewis, Ilex paraguariensis A. St-Hil., Lippia Alba Mill. N.E.Br., Maytenus ilicifolia Martius ex Reissek, Passiflora edulis Sims., Phyllanthus niruri L., Schinus terebinthifolius Raddi e Symphytum officinale L. foram as espécies mais relatadas na literatura pesquisada.

\section{AGRADECIMENTOS}

Os autores agradecem o CNPq pelo auxílio financeiro concedido. 
Quadro 2. Condições operacionais de secagem por aspersão, utilizadas nos estudos descritos.

\begin{tabular}{|c|c|c|c|}
\hline Autor (ano) & Equipamento & Condições operacionais & Adjuvante de secagem \\
\hline Abadio, 2004 & $\begin{array}{l}\text { escala piloto, aspersor de } \\
\text { disco e fluxo co-corrente }\end{array}$ & $\begin{array}{l}\text { Temperatura de entrada: } 190{ }^{\circ} \mathrm{C} \\
\text { Temperatura de saída: } 90{ }^{\circ} \mathrm{C} \\
\text { Velocidade do aspersor: } 25.000 \mathrm{rpm} \\
\text { Taxa de alimentação: } 0,18 \mathrm{~kg} / \mathrm{min}\end{array}$ & Maltodextrina \\
\hline Da Silva, 2007 & Production Minor Niro & $\begin{array}{l}\text { Temperatura de entrada: } 177 \pm 1{ }^{\circ} \mathrm{C} \\
\text { Temperatura de saída: } 99,3{ }^{\circ} \mathrm{C} \\
\text { Taxa de alimentação: } 143 \mathrm{~mL} / \mathrm{min} \\
\text { Velocidade do aspersor: } 10900 \mathrm{rpm} \\
\text { Diferença de pressão: } 125 \mathrm{mmHg}\end{array}$ & $\begin{array}{l}\text { Aerosil }^{\circledR} \text { (Dióxido de silício } \\
\text { coloidal), Avicel }^{\circledR} \text { (celuose } \\
\text { microcristalina) Glucidex } \\
\text { (maltodextrina) }\end{array}$ \\
\hline De Souza et al., 2006b & $\begin{array}{c}\text { Mini Spray Dryer } \\
\text { Büchi } 189\end{array}$ & $\begin{array}{l}\text { Temperatura de entrada: } 150{ }^{\circ} \mathrm{C} \\
\text { Temperatura de saída: } 90^{\circ} \mathrm{C} \\
\text { Taxa de alimentação: } 3 \mathrm{~mL} / \mathrm{min} \\
\text { Pressão: } 2 \text { bar }\end{array}$ & - \\
\hline De Souza et al., 2007 & $\begin{array}{c}\text { Mini Spray Dryer } \\
\text { Büchi } 190\end{array}$ & $\begin{array}{c}\text { Temperatura de entrada: } 157 \text { a } 160{ }^{\circ} \mathrm{C} \\
\text { Taxa de alimentação: } 3 \mathrm{~mL} / \mathrm{min} \\
\text { Pressão: } 2 \text { bar }\end{array}$ & $\begin{array}{l}\text { Dióxido de silício coloidal } \\
\qquad(50 \%)\end{array}$ \\
\hline Georgetti et al., 2008 & Labplant SD-05 & $\begin{array}{c}\text { Temperatura de entrada: } 150{ }^{\circ} \mathrm{C} \\
\text { Taxa de alimentação: } 4 \mathrm{~g} / \mathrm{min} \\
\text { Fluxo de ar: } 0,0227 \mathrm{~kg} / \mathrm{s} \\
\text { Pressão: } 1 \text { bar }\end{array}$ & $\begin{array}{l}\text { Dióxido de silício coloidal, } \\
\text { maltodextrina e amido }\end{array}$ \\
\hline Petrovick, 2006 & Production Minor Niro & $\begin{array}{l}\text { Temperatura de entrada: } 175 \pm 2{ }^{\circ} \mathrm{C} \\
\text { Temperaturas de saída: } 100 \pm 1{ }^{\circ} \mathrm{C} \\
\text { Taxa de alimentação: } 160 \mathrm{~mL} / \mathrm{min} \\
\text { Velocidade do aspersor: } 11000 \mathrm{rpm} \\
\text { Diferença de pressão: } 125 \mathrm{mmHg}\end{array}$ & $\begin{array}{c}\text { Dióxido de silício coloidal } \\
\left.\text { (Aerosil }{ }^{\circledR} 200\right) \text { e Polissorbato } \\
80\left(\text { Tween }^{\circledR} 80\right)-50 \%\end{array}$ \\
\hline Quek et al., 2007 & $\begin{array}{c}\text { Mini Spray Dryer } \\
\text { Büchi } 191\end{array}$ & $\begin{array}{l}\text { Temperaturas de entrada: } 145,155,165 \text { e } \\
175^{\circ} \mathrm{C} \text {. } \\
\text { Temperatura de saída: } 94,7 \text { a } 112,7^{\circ} \mathrm{C} \\
\text { Taxa de alimentação: } 600 \mathrm{~L} / \mathrm{h} \\
\text { Pressão: } 4,5 \text { bar }\end{array}$ & $\begin{array}{c}\text { Maltodextrina } \\
\text { (concentrações de } 3 \text { e } 5 \% \text { ) }\end{array}$ \\
\hline Soares, 2002 & Production Minor Niro & $\begin{array}{l}\text { Temperatura de entrada: } 149 \pm 1{ }^{\circ} \mathrm{C} \\
\text { Temperatura de saída: } 99 \pm 1{ }^{\circ} \mathrm{C} \\
\text { Taxa de alimentação: } 140 \mathrm{~mL} / \mathrm{min} \\
\text { Velocidade do aspersor: } 9500 \mathrm{rpm}\end{array}$ & $\begin{array}{l}\text { Dióxido de silício colloidal } \\
\quad\left(\text { Aerosil }{ }^{\circledR} 200\right)-20 \%\end{array}$ \\
\hline Spaniol, 2007 & Production Minor Niro & $\begin{array}{l}\text { Temperatura de entrada: } 177,2 \pm 1^{\circ} \mathrm{C} \\
\text { Temperaturas de saída: } 99,3 \pm 1{ }^{\circ} \mathrm{C} \\
\text { Taxa de alimentação: } 143 \mathrm{~mL} / \mathrm{min} \\
\text { Velocidade do aspersor: } 10900 \mathrm{rpm} \\
\text { Diferença de pressão: } 125 \mathrm{mmHg}\end{array}$ & Aerosil $^{\circledR} 200$ \\
\hline Su et al.,2008 & $\begin{array}{l}\text { Mini Spray Dryer Büchi } \\
290\end{array}$ & $\begin{array}{l}\text { Temperatura de entrada: } 80^{\circ} \mathrm{C} \text {, Fluxo } \\
\text { de alimentação: } 4 \mathrm{~mL} / \mathrm{min} \text { Fluxo de gás: } \\
357 \mathrm{~L} / \mathrm{h}\end{array}$ & Gelatina e carmelose sódica \\
\hline Tonon et al., 2008 & LabPlant SD-05 & $\begin{array}{c}\text { Temperaturas de entrada: } 138 \text { a } 202{ }^{\circ} \mathrm{C} \\
\text { Taxa de alimentação: } 5 \text { a } 25 \mathrm{~g} / \mathrm{min} \\
\text { Fluxo de ar: } 73 \mathrm{~m} 3 / \mathrm{h} \\
\text { Pressão: } 0,06 \mathrm{MPa}\end{array}$ & $\begin{array}{c}\text { Maltodextrina } \\
\text { (concentrações de } 10 \text { a 30\%) }\end{array}$ \\
\hline $\begin{array}{l}\text { Vasconcelos et al., } \\
2005\end{array}$ & $\begin{array}{c}\text { Mini Spray Dryer } \\
\text { Büchi } 191\end{array}$ & $\begin{array}{l}\text { Temperatura de entrada: } 120 \text { a } 160{ }^{\circ} \mathrm{C} \\
\text { Temperatura de saída: } 95{ }^{\circ} \mathrm{C} \\
\text { Taxa de alimentação: } 7,0 \mathrm{~mL} / \mathrm{min} \\
\text { Pressão: } 600 \mathrm{mmHg}\end{array}$ & $\begin{array}{l}\text { Aerosil }^{\circledR} 200 \text { (Dióxido de } \\
\text { silício coloidal) e Kleptose }{ }^{\circledR} \\
\quad(\beta \text {-ciclodextrina) }\end{array}$ \\
\hline Zétola et al., 2002 & $\begin{array}{c}\text { Mini Spray Dryer } \\
\text { Büchi } 190\end{array}$ & $\begin{array}{l}\text { Temperatura de entrada: } 143{ }^{\circ} \mathrm{C} \pm 2 \\
\text { Temperatura de saída: } 105^{\circ} \mathrm{C} \pm 2 \\
\text { Taxa de alimentação: } 3 \mathrm{~mL} / \mathrm{min} \\
\text { Pressão: } 2 \text { bar }\end{array}$ & $\begin{array}{c}\text { Dióxido de silício } \\
\text { coloidal, Polissorbato } 80 \text { e } \\
\beta \text {-ciclodextrina }\end{array}$ \\
\hline
\end{tabular}




\section{REFERÊNCIAS}

Abadio FDB, Domingues AM, Borges SV, Oliveira VM 2004. Physical properties of powdered pineapple (Ananas comosus) juice - effect of malt dextrin concentration and atomization speed. J Food Eng 64: 285-287.

Alamilla-Beltrán L, Chanona-Pérez JJ, Jiménez-Aparicio AR, Gutiérrez-López GF 2005. Description of morphological changes of particles along spray-drying. J Food Eng 67: 79-184.

Aulton ME 2002. Pharmaceutics: The Science of Dosage Form Design. 2 ed. Edinburg: Churchill Livingstone, p. 388390.

Bersani-Amado CA, Massao LB, Baggio SR, Johanson L, Albiero ALM, Kimura E 2000. Antiulcer effectiveness of Maytenus aquifolium spray dried extract. Phytother Res 14: 543-545.

Broadhead J, Edmond Rouan SK, Rhodes CT 1992. The spray drying of pharmaceuticals. Drug Dev Ind Pharm 18: 1169-1206.

Cao XQ, Vassen R, Schwartz S, Jungen W, Tietz F, Stöever D 2000. Spray-drying of ceramics for plasma-spray coating. J Eur Ceram Soc 20: 2433-2439.

Carvalho ELS 1997. Desenvolvimento de produtos secos nebulizados de Maytenus ilicifolia Martius ex Reissek - Celastraceae (espinheira-santa). Porto Alegre, 133p. Dissertação de mestrado, Programa de Pós-graduação em Ciências Farmacêuticas, UFRGS.

Carvalho ACB, Balbino EE, Maciel A, Perfeito JPS 2008. Situação do registro de medicamentos fitoterápicos no Brasil. Rev Bras Farmacogn 18: 314-319.

Çelik M, Wendel SC 2005. Spray drying and pharmaceutical applications. In: DM Parikh. Handbook of pharmaceutical granulation technology. 2 Ed., Boca Raton: Taylor \& Francis Group, p. 129-158.

Couto AG 2005. Desenvolvimento tecnológico de comprimidos a partir do granulado do produto seco por aspersão de Phyllanthus niruri e controle de qualidade da matériaprima vegetal a partir do seu cultivo. Porto Alegre, 456p. Tese de doutorado, Programa de Pós-graduação em Ciências Farmacêuticas, UFRGS.

Da Silva FA 2007. Avaliação tecnológica e atividade antioxidante de produtos secos por spray-drying de Ilex paraguariensis A. St. Hill. - Aquifoliaceae (erva-mate). Porto Alegre, 243p. Tese de doutorado, Programa de Pós-graduação em Ciências Farmacêuticas, UFRGS.

De Campos AM 1996. Desenvolvimento de extratos secos nebulizados de Ilex paraguariensis St. Hill. Aquifoliaceae (erva-mate). Porto Alegre, 149p. Dissertação de mestrado, Programa de Pós-graduação em Ciências Farmacêuticas, UFRGS.

De Medeiros ACD, De Medeiros IA, Macêdo RO 2002. Thermal studies of Albizia inopinata crude extract in the presence of cyclodextrin and Aerosil ${ }^{\circledR}$ by TG and DSC coupled to the photovisual system. Termochim Acta 392-393: 93 98.

De Paula IC, González Ortega G, Bassani VL, Petrovick PR 1998. Development of ointment formulations prepared with Achyrocline satureioides spray-dried extracts. Drug Dev Ind Pharm 24: 235-241.

De Souza KCB 1997. Desenvolvimento de metodologia analiticas e tecnológicas na obtenção de extratos secos nebulizados de Passiflora edulis forma flavicarpa. Porto Alegre, 141p. Dissertação de mestrado, Programa de Pós-graduação em Ciências Farmacêuticas, UFRGS.

De Souza KCB, Petrovick PR, Bassani VL, Gonzalez Ortega G 2000. The adjuvants Aerosil 200 and Gelita-Sol-P influence on the technological characteristics of spraydried powders from Passiflora edulis var. flavicarpa. Drug Dev Ind Pharm 26: 331-336.

De Souza KCB, Schapoval EES, Bassani VL 2002. LC determination of flavonoids: separation of quercetin, luteolin and 3-O-methylquercetin in Achyrocline satureioides preparations. J Pharmaceut Biomed 28: 771-777.

De Souza KCB, Bassani VL, Schapoval EES 2007. Influence of excipients and technological process on antiinflammatory activity of quercetin and Achyrocline satureioides (Lam.) D.C. extracts by oral route. Phytomedicine 14: 102-108.

De Souza TP, Spaniol B, Petrovick PR 2005. Avaliação de comprimidos revestidos por película contendo alta concentração de produto seco por aspersão de Phyllanthus niruri. Acta Farm Bonaerense 24: 61-67.

De Souza TP, Gomez-Amoza JL, Martínez-Pacheco R, Petrovick PR 2006a. Compressional behavior of formulations from Phyllanthus niruri spray dried extract. Die Pharmazie 61: 213-217.

De Souza TP, Lionzo MIZ, Petrovick PR 2006b. Avaliação da redução da carga microbiana de droga vegetal através do processamento tecnológico: decocção e secagem por aspersão. Rev Bras Farmacogn 16: 94-98.

De Souza TP, Martínez-Pacheco R, Gomez-Amoza JL, Petrovick PR 2007. Eudragit E as excipient for the production of granulates and tablets containing high load of a spray dried Phyllanthus niruri L. extract. AAPS PharmSci 8: E1-E7.

Filková I, Mujumdar AS 1987. Industrial spray drying systems. In: Mujundar AS. Handbook of Industrial Drying. Nova York: Dekker, p. 243-292.

Foster TP, Leatherman MW 1995. Powder characteristics of proteins spray-dried from different spray-dryers. Drug Dev Ind Pharm 21: 1705-1723.

Georgetti SR, Casagrande R, De Souza CRF, de Oliveira WP, Fonseca MJV 2008. Spray drying of the soybean extract: effects on chemical properties and antioxidant activity. Food Sci Technol 41: 1521-1527.

Linden R, González Ortega G, Petrovick PR, Bassani VL 2000. Response surface analysis applied to the preparation of tablets containing a high concentration of vegetable spray-dried extract. Drug Dev Ind Pharm 26: 441-446.

List PH, Schmidt PC 1989. Phytopharmaceutical Technology. Boca Raton: CRC Press, p. 320-334.

Masters K 1985. Spray Drying Handbook. 4. ed. Londres: George Godwin.

Mujumdar AS 2000. Dryers for Particulate Solids, Slurries and Sheet-form Materials. In: Devahastin S. Mujumdar's Practical Guide to Industrial Drying. Quebec: Exergex, p. 37-61.

Nonhebel G, Moss AAH 1971. Drying of Solids in the Chemical Industry. Londres: Butterworths, p. 253-263.

Oliveira OW 2008. Parâmetros de produção e caracterização de produto seco de Maytenus ilicifolia Mart. ex Reissek Celastraceae em torre de secagem por aspersão. Porto Alegre, 91p. Dissertação de mestrado, Programa de Pós- 
graduação em Ciências Farmacêuticas, UFRGS, p. 1314.

Petrovick GF 2006. Desenvolvimento e avaliação tecnológica de granulado revestido contendo produto seco por spray drying de Achyrocline satureioides (Lam) D.C. Asteraceae (marcela). Porto Alegre, 200p. Dissertação de mestrado, Programa de Pós-graduação em Ciências Farmacêuticas, UFRGS.

Quek SY, Chok NK, Swedlund P 2007. The physicochemical properties of spray-dried watermelon powders. Chem Eng Process 46: 386-392.

Rankell AS, Lieberman HÁ, Schiffman RF 2001. Secagem. In: Lachman L, Lieberman HA, Kanig JL. Teoria e prática na indústria farmacêutica. Vol 1. Lisboa: Calouste Gulbenkian, p. 83-112.

Santos EVM 2000. Extração de matérias-primas vegetais. In: Sharapin N. Fundamentos tecnológicos de produtos fitoterápicos. Bogotá: Andrés Bello, p. 57-60.

Shaw FV 1997. Spray drying as an alternative granulation technique. In: Parikj DM. Handbook of Pharmaceutical Granulation Technology. Nova York: Marcel Dekker, p. 75-96.

Silva Júnior JOC, Vieira JLF, Barbosa WLR, Pereira NL 2006. Caracterização físico-química do extrato fluido e seco por nebulização de Symphytum officinale L. Rev Bras Farmacogn 16(Supl.): 671-677.

Soares LAL 2002. Obtenção de comprimidos contendo alto teor de produto seco por aspersão de Maytenus ilicifolia Mart. ex Reissek-Celastraceae. Desenvolvimento tecnológico de produtos intermediários e final. Porto Alegre, 285p. Tese de doutorado, Programa de Pós-graduação em Ciências Farmacêuticas, UFRGS.

Soares LAL, González Ortega G, Petrovick PR, Schmidt PC 2005. Dry granulation and compression of spray-dried plant extracts. AAPS Pharmsci 6: E359-E366.

Souza CRF, Schiavetto IA, Thomazini FCF, de Oliveira WP 2008. Processing of Rosmarinus officinalis Linné extract on spray and spouted bed dryers. Braz J Chem Eng 25: 59-69.

Spaniol B 2007. Comparação do comportamento compressional de granulado contendo produto seco por aspersão de Phyllantus niruri L. entre máquinas de comprimir alternativa e rotativa. Porto Alegre, 186p. Dissertação de mestrado, Programa de Pós-graduação em Ciências Farmacêuticas, UFRGS.

Su YL, Fu ZY, Zhang JY, Wang WM, Wang H, Wang YC, Zhang QJ 2008. Microencapsulation of radix Salvia miltiorrhiza nanoparticles by spray-drying. Powder Technol 184: 114-121.

Teixeira HF 1996. Avaliação da influência de adjuvantes farmacêuticos sobre características físicas, químicas, tecnológicas e farmacológicas de extratos secos nebulizados de Achyrocline satureioides (LAM) DC. Compositae - Marcela. Porto Alegre, 146p. Dissertação de mestrado, Programa de Pós-graduação em Ciências Farmacêuticas, UFRGS.

Tonon RV, Brabet C, Hubinger, MD 2008. Influence of process conditions on the physicochemical properties of açai (Euterpe oleraceae Mart.) powder produced by spray drying. J Food Eng 88: 411-418.

Vasconcelos EAF, Medeiros MGF, Raffin FN, Moura TFAL 2005. Influência da temperatura de secagem e da concentração de Aerosil $^{\circledR} 200$ nas características dos extratos secos por aspersão da Schinus terebinthifolius Raddi (Anacardiaceae). Rev Bras Farmacogn 15: 243249.

Wendel S, Çelik M 1998. Uma visão geral sobre o uso da tecnologia de spray-drying. Pharmaceutical Technol Abril: 31-45.

Zétola M, de Lima TCM, Sonaglio D, González-Ortega G, Limberger RP, Petrovick PR, Bassani VL 2002. CNS activities of liquid and spray-dried extracts from Lippia alba - Verbenaceae (Brazilian false melissa). $J$ Ethnopharmacol 82: 207-215. 